\title{
PENGENDALIAN MIOPIA PADA ANAK
}

\author{
Wanda Feranti Siregar \\ Fakultas Kedokteran, Universitas Lampung, Jl. Prof. DR. Ir. Sumatri Brojonegoro No.1, Gedong Meneng, \\ Kec. Rajabasa, Kota Bandar Lampung, Lampung, Indonesia 35145 \\ wandaferanti29@gmail.com (+6282272595913)
}

\begin{abstract}
ABSTRAK
Memperlambat perkembangan miopia telah menjadi perhatian besar bagi orang tua dari anak-anak penderita miopi. Dewasa ini, ilmu klinis dengan cepat mengembangkan pengetahuan tentang metode untuk memperlambat perkembangan miopia. Oleh karena itu, literatur review ini bertujuan untuk mengetahui strategi terapeutik baru untuk mengoreksi dan membatasi perkembangan miopia pada kelompok usia anak-anak. Penelitian ini merupakan literature review yang melibatkan sebanyak 15 sumber pustaka dengan kata kunci yang digunakan 'myopia dan pediatric' dengan tahun terbit antara 2001 - 2021. Abstrak dan full text jurnal dibaca kemudian dicermati, selanjutnya dilakukan analisis terhadap isi dalam tujuan penelitian dan hasil/temuan penelitian. Berbagai penelitian menunjukkan pilihan tatalaksana seperti undercorrection miopia, lensa kontak alignment fit gas-permeable, dan kacamata bifokal atau multifokal telah terbukti tidak efektif untuk pengendalian miopia. Metode yang paling efektif adalah penggunaan lensa kontak ortokeratologi, lensa kontak bifokal lunak, dan agen farmasi topikal seperti atropin atau pirenzepine.
\end{abstract}

Kata kunci: anak; myopia; pediatrik

\section{MYOPIA CONTROL IN CHILDREN}

\begin{abstract}
Slowing the progression of myopia has become a major concern for parents of children with myopia. Today, clinical science is rapidly expanding knowledge of methods to slow the progression of myopia. Therefore, this literature review aims to identify new therapeutic strategies to correct and limit the development of myopia in the pediatric age group. This research is a literature review involving as many as 15 literature sources with the keywords used 'myopia and pediatrics' with the year published between 2001 - 2021. Abstracts and full text journals are read and examined, then an analysis of the content in the research objectives and results/findings is carried out. Various studies have shown that treatment options such as undercorrection of myopia, gas-permeable alignment-fit contact lenses, and bifocal or multifocal glasses have been shown to be ineffective for myopia control. The most effective methods are the use of orthokeratological contact lenses, soft bifocal contact lenses, and a topical pharmaceutical agent such as atropine or pirenzepine.
\end{abstract}

Keywords: children; myopia; pediatric

\section{PENDAHULUAN}

Miopia umumnya dikenal sebagai rabun jauh, merupakan keadaan refraksi di mana sinar paralel cahaya yang datang dari jarak jauh difokuskan di depan retina karena memiliki panjang aksial maupun arkus kornea yang curam. Hal ini adalah penyebab utama gangguan refraksi yang dapat dikoreksi dan kebutaan yang dapat dicegah (Belete et al., 2017). Gambaran klinis miopia meliputi penurunan kemampuan 
penglihatan jarak jauh, penglihatan warna berkurang dan sensitivitas kontras (L. J. Wu et al., 2015). Miopia adalah hasil dari kombinasi faktor genetik dan lingkungan, tetapi peningkatan prevalensi miopia selama abad terakhir di masyarakat tertentu sangat mendukung pengaruh lingkungan yang lebih besar. Hal ini telah dikaitkan dengan faktor usia, jenis kelamin, intensitas sekolah, riwayat keluarga miopia, waktu untuk aktivitas di luar ruangan, jenis sekolah, dan paparan aktivitas kerja dekat. Karena tidak ada metode yang diterima secara universal untuk pencegahan onset miopia, penting untuk mengidentifikasi faktor risiko yang dapat dimodifikasi yang terkait dengan perkembangannya (Assem et al., 2021).

Miopia muncul dengan prevalensi yang lebih besar pada anak-anak, sehingga menempatkan anak-anak ini pada risiko yang lebih besar untuk mengembangkan miopia tinggi (Assem et al., 2021). Miopia pediatrik mempengaruhi sekitar $23 \%$ populasi di seluruh dunia dengan prevalensi antara $0,9 \%$ hingga 3,1\%. Morbiditas mata terkait dengan pertumbuhan aksial mata, yang merupakan penyebab penting dari disfungsi penglihatan permanen. Miopia biasanya bermanifestasi di masa anakanak, antara usia 7 hingga 10 tahun, dan setelah itu, berkembang selama 10 hingga 15 tahun berikutnya. Prevalensi miopia parah meningkat di daerah perkotaan Asia dan penelitian terbaru menunjukkan situasi yang sama di AS dan banyak populasi lain (T,one et al., 2020).

Prevalensi terus meningkat dan usia onset yang menurun, kondisi tersebut dapat menyebabkan perkembangan dan risiko gangguan miopia yang tinggi serta komplikasi mata lainnya akan lebih mungkin terjadi (Morgan et al., 2018). Sehingga, tatalaksana untuk membatasi perkembangan miopia akan sangat bermanfaat, namun dengan tidak adanya protokol pengobatan resmi, terdapat variasi yang signifikan dalam pola pengobatan di antara dokter mata anak untuk mengurangi perkembangan miopia (T,one et al., 2020). Oleh karena itu, literatur review ini bertujuan untuk mengetahui strategi terapeutik untuk mengoreksi dan membatasi perkembangan miopia pada kelompok usia anak-anak.

\section{METODE}

Artikel ini merupakan studi literature review, yang menyajikan kembali materi yang diterbitkan sebelumnya, dan melaporkan fakta atau analisis baru. Penelusuran sumber pustaka dalam artikel ini melalui database PubMed dan Google Scholar. Sumber pustaka yang digunakan dalam penyusunan melibatkan 15 pustaka dengan kata kunci yang digunakan dalam penelusuran antara lain 'myopia dan pediatric'. Pemilihan artikel sumber pustaka dilakukan dengan melakukan peninjauan pada judul, abstrak dan hasil yang membahas strategi terapeutik untuk mengoreksi miopia. Abstrak dan teks lengkap jurnal dibaca kemudian dicermati, selanjutnya dilakukan analisis terhadap isi dalam tujuan penelitian dan hasil/temuan penelitian. Setelah itu dilakukan koding terhadap isi jurnal yang direview berdasarkan garis besar atau inti dari penelitian tersebut yang dilakukan dengan mengurai dalam sebuah kalimat, dan jika sudah terkumpul kemudian dicari persamaan dan perbedaan pada masingmasing penelitian lalu dibahas untuk menarik kesimpulan. 
HASIL

Melakukan pekerjaan dengan jarak dekat telah lama diduga menjadi faktor risiko miopia, beberapa penelitian telah menemukan korelasi yang kuat dengan onset atau perkembangan miopia. Menghabiskan lebih banyak waktu di luar ruangan telah terbukti mengurangi kemungkinan menjadi miopia, tetapi tidak memperlambat perkembangan miopia. Beberapa sekolah di Taiwan secara acak ditugaskan untuk melakukan kegiatan di luar ruangan selama istirahat, sementara sekolah lain mempertahankan rutinitas normalnya selama jam istirahat. Di sekolah yang mendorong lebih banyak kegiatan di luar ruangan selama jam istirahat, hanya $8,4 \%$ anak menjadi miopia, dibandingkan dengan $17,7 \%$ di sekolah yang mempertahankan kegiatan istirahat normal mereka (P, 0,001) (P. C. Wu et al., 2013)

Penelitian oleh Lam et al (2014) dilakukan pada 221 anak usia 8-13 tahun, dengan miopia antara -1.00 dan 5.00 dioptri (D) dan astigmatisme $\leq 1.00$ D. Subjek secara acak dikelompokkan untuk menggunakan Defocus Incorporated Soft Contact (DISC) ( $\mathrm{n}=$ 111) dan kelompok lensa kontak $(n=110)$. Kesalahan bias (autorefraksi cycloplegic) dan panjang aksial mata diukur pada interval 6 bulan. Miopia berkembang $25 \%$ lebih lambat untuk anak-anak dalam kelompok DISC dibandingkan dengan kelompok kontrol $(\mathrm{p}=0,031)$. Demikian juga terdapat lebih sedikit perpanjangan aksial untuk anak-anak di kelompok DISC dibanding kontrol $(\mathrm{p}=0,009)$. Miopia pada anakanak yang memakai lensa DISC selama lima jam atau lebih / hari berkembang $46 \%$ lebih rendah dibandingkan kelompok kontrol $(\mathrm{p}=0,001)$. Pemakaian lensa DISC setiap hari secara signifikan memperlambat perkembangan miopia dan perpanjangan aksial pada anak-anak. Temuan menunjukkan bahwa penglihatan yang jelas secara simultan dengan defokus miopia yang konstan dapat memperlambat perkembangan miopia (Lam et al., 2014).

\section{PEMBAHASAN}

Beberapa penelitian telah menunjukkan hubungan antara peningkatan aktivitas penglihatan jarak dekat dan miopia, meskipun hubungan ini belum diamati secara konsisten. Dalam studi miopia di Sydney, anak-anak berusia 12 tahun yang membaca dengan jarak kurang dari $30 \mathrm{~cm}$ dan terus menerus selama lebih dari 30 menit memiliki 2,5 dan 1,5 kali lebih mungkin untuk mengembangkan miopia, meskipun jumlah total waktu yang dihabiskan untuk pekerjaan tidak signifikan. Demikian pula, dalam sebuah penelitian yang dilakukan di siswa sekolah menengah Beijing yang berusia 16 hingga 18 tahun, prevalensi miopia yang lebih tinggi dikaitkan dengan waktu yang lebih lama dihabiskan di dekat tempat kerja dan jarak dekat kerja yang lebih pendek (L. J. Wu et al., 2015). Jumlah miopia yang lebih tinggi meningkatkan risiko komplikasi mata seperti glaukoma, katarak, dan ablasi retina serta atrofi. Karena komplikasi yang mengancam penglihatan ini dan tingginya prevalensi di seluruh dunia, para ilmuwan telah mencoba banyak metode untuk mengurangi perkembangan rabun jauh, termasuk koreksi kesalahan bias miopik, kacamata bifokal atau multifokal, lensa kontak alignment fit gas-permeable, agen farmasi topikal, lensa kontak ortokeratologi, dan lensa kontak bifokal lunak (Smith \& Walline, 2015). 
Lensa Single Vision (LSV) mewakili pilihan terapeutik yang paling sering digunakan untuk mengobati miopia. Meskipun metode ini membantu meningkatkan ketajaman visual, metode ini tidak mengurangi perkembangan miopia atau pertumbuhan aksial mata. Selain itu, telah ditunjukkan bahwa penggunaan LSV mungkin mendukung progresi miopia dan perpanjangan aksial mata. Kemudian, tidak jelas mengapa mata yang tidak dikoreksi berkembang lebih cepat dari biasanya, tetapi koreksi yang kurang jelas bukan merupakan strategi pengobatan yang efisien. Selain itu, direkomendasikan bahwa pasien dengan miopia progresif harus dievaluasi secara teratur. Lensa tambahan alternatif terapi lain yang melawan perkembangan miopia adalah penggunaan lensa bifokal dan Progressive Additional Lenses (PAL). Dengan mengurangi akomodasi yang terkait dengan penglihatan jarak dekat, dapat menghilangkan keterlambatan akomodasi dan defokus hiperopik berturut-turut di fovea (T,one et al., 2020).

Lensa MyoVision merupakan lensa penglihatan tunggal dengan desain manajemen miopia spesifik yang efektif dalam mencegah perkembangan miopia. Pinggiran lensa bertanggung jawab atas kendali miopia, sedangkan bagian tengah memberikan penglihatan tajam untuk mengoreksi miopia. Pada LSV, bagian tengahnya berfungsi dengan baik tetapi bagian pinggiran lensa sering kali memproyeksikan gambar di belakang area visual. Hal ini dapat menyebabkan sinyal ke mata memanjang, sehingga mendukung perkembangan miopi.

Tepi lensa MyoVision dapat mengoreksi pengaburan penglihatan dan akibatnya dapat membantu membatasi perkembangan miopi. Uji coba efektivitas lensa ini selama 12 bulan pada 210 anak sekolah di China menghasilkan pembatasan perkembangan miopia sebesar $30 \%$ pada anak-anak berusia antara 6 dan 12 tahun. Progresi berkurang secara signifikan sebesar 0,29 D diidentifikasi pada mata yang memakai lensa asimetris-rotasi dibandingkan kelompok kontrol (Sankaridurg et al., 2010). Namun yang dilakukan di Jepang barubaru ini pada 207 pasien dengan usia antara 6 dan 12 tahun dengan refraksi bola yang setara mulai dari -1,5 hingga 4,5 dioptri, tidak dapat memverifikasi efek terapeutik dari jenis lensa ini dalam membatasi evolusi miopia. Sehingga studi tambahan diperlukan untuk merancang lensa yang dapat menurunkan defokus hiperopik perifer secara individual dan untuk menganalisis manfaat lensa ini dalam mencegah perkembangan miopia (Kanda et al., 2018).

Sementara itu, lensa kontak ortokeratologi telah diketahui dapat memperlambat pertumbuhan aksial mata dengan rata-rata $43 \%$. Sebuah studi crossover mata kontralateral selama 6 bulan menemukan pengurangan panjang mata 0,0460,08 mm untuk mata yang memakai lensa kontak ortokeratologi dan pemanjangan aksial 0,0960,09 $\mathrm{mm}$ pada mata yang memakai lensa kontak alignment fit gaspermeable(Swarbrick et al., 2015). Penelitian serupa juga dilakukan di Hong Kong, uji klinis acak tersebut melaporkan pemanjangan aksial $0,3660,24 \mathrm{~mm}$ pada kelompok ortokeratologi dan $0,6360,26 \mathrm{~mm}$ pada kelompok single vision spectacle $(\mathrm{P}$, 0,01). Kelompok yang sama juga membandingkan perkembangan miopia antara subjek dengan miopia $-5,00 \mathrm{D}$ atau lebih yang dikoreksi baik dengan kombinasi lensa kontak ortokeratologi 
(tujuan pengobatan 4,00 D) dan kacamata LSV atau hanya dengan LSV saja. Mata yang memakai lensa kontak ortokeratologi dan LSV tumbuh 0,1960,1 $\mathrm{mm}$, dibandingkan dengan $0,5160,32 \mathrm{~mm}$ untuk yang hanya memakai LSV $(\mathrm{P}=0,005)$ (Charm \& Cho, 2013). (Walline, 2016)

Atropin topikal juga diketahui telah menunjukkan penurunan yang signifikan secara statistik dan klinis dalam perkembangan miopia, didukung oleh banyak studi. Shih et al melakukan studi acak pada anak-anak dengan usia antara 6 dan 13 tahun, membandingkan penggunaan atropin $0,5 \%$ dan kacamata multifokal, kacamata multifokal saja atau LSV saja. Studi tersebut melaporkan hasil yang lebih baik pada kelompok atropin $(0,41 \mathrm{D}$ vs $1,19 \mathrm{D}$ dan 1,40 D) (Shih et al., 2001; T,one et al., 2020).

Chua et al (2006) melaporkan hasil yang sama dalam studi selama dua tahun terhadap 400 peserta, anak-anak dengan miopia berusia 6 sampai 12 tahun di Singapura. Studi tersebut membandingkan kelompok atropin dengan kelompok kontrolplasebokontrol. Studi ini diikuti oleh uji klinis 5 tahun yang menganalisis kemanjuran atropin dosis kecil dalam membatasi evolusi miopia, juga untuk meminimalkan efek samping. Pasien menerima atropin $0,5 \%$ atau $0,1 \%$ atau $0,01 \%$ selama 2 tahun, diikuti dengan periode washing out selama 1 tahun. Kesimpulannya didapatkan bahwa ketiga dosis atropin tetap efisien dalam menurunkan progresi miopia dan konsentrasi $0,01 \%$ memiliki efek samping paling kecil (Chua et al., 2006; Ţone et al., 2020). Meskipun atropin digunakan di banyak negara di Asia untuk membatasi perkembangan miopia, atropin jarang digunakan di AS dan Eropa karena efek samping jangka pendek dan jangka panjang. Efek samping yang terkait dengan atropin adalah fotofobia, sikloplegia, dermatitis alergi, peningkatan tekanan intraokular, katarak dan glaukoma sudut tertutup dan sebaiknya tidak direkomendasikan untuk penggunaan jangka panjang. Pirenzepine digunakan sebagai pengobatan alternatif untuk miopia pediatrik, lebih kecil kemungkinannya menyebabkan mydriasis atau cycloplegia dan memiliki efek samping yang lebih sedikit. Pirenzepine mungkin memiliki peran positif dalam memperlambat perkembangan miopia pada anak-anak (T,one et al., 2020).

\section{SIMPULAN}

Dari semua metode yang dipelajari untuk memperlambat perkembangan miopia, agen farmasi topical, lensa kontak ortokeratologi dan lensa kontak bifokal lunak ditemukan sebagai modalitas yang paling efektif dan tersedia secara komersial. Namun, tidak satupun yang disetujui oleh FDA untuk memperlambat perkembangan miopia. Obat-obatan topikal tidak sering digunakan karena efek sampingnya, terutama fotofobia dan berkurangnya penglihatan dekat dan akomodasi, tetapi ada potensi pengendalian miopia dengan efek samping yang lebih sedikit menggunakan konsentrasi yang lebih rendah. Lensa kontak ortokeratologi dan lensa kontak bifokal lunak memperlambat perkembangan miopia dengan cara yang sama, sehingga modalitas terbaik harus ditentukan oleh praktisi perawatan mata dan orang tua. Kacamata bifokal dan multifokal secara statistik signifikan dalam memperlambat perkembangan miopia, tetapi tidak memberikan efek yang bermakna secara klinis. Sedangkan koreksi miopia dan lensa kontak alignment fit gas-permeable tidak 
ditemukan memperlambat perkembangan miopia pada anak-anak.

\section{DAFTAR PUSTAKA}

Assem, A. S., Tegegne, M. M., \&Fekadu, S. A. (2021). Prevalence and associated factors of myopia among school children in Bahir Dar city, Northwest Ethiopia, 2019. Plos One, 16(3), e0248936.

https://doi.org/10.1371/journal.po ne.0248936

Belete, G. T., Anbesse, D. H., Tsegaye, A. T., \& Hussen, M. S. (2017). Prevalence and associated factors of myopia among high school students in Gondar town, northwest Ethiopia, 2016. Clinical Optometry, 9, 11-18. https://doi.org/10.2147/OPTO.S12 0485

Charm, J., \& Cho, P. (2013). High Myopia Y Partial Reduction Ortho-k: A 2-Year. Optometry and Vision Science, 90(6), 530539.

Chua, W. H., Balakrishnan, V., Chan, Y. H., Tong, L., Ling, Y., Quah, B. L., \& Tan, D. (2006). Atropine for the Treatment of Childhood Myopia. Ophthalmology, 113(12), 2285-2291.

https://doi.org/10.1016/j.ophtha.2 006.05.062

Kanda, H., Oshika, T., Hiraoka, T., Hasebe, S., Ohno-Matsui, K., Ishiko, S., Hieda, O., Torii, H., Varnas, S. R., \& Fujikado, T. (2018). Effect of spectacle lenses designed to reduce relative peripheral hyperopia on myopia progression in Japanese children: a 2-year multicenter randomized controlled trial. Japanese Journal of Ophthalmology, 62(5), 537543.

https://doi.org/10.1007/s10384018-0616-3

Lam, C. S. Y., Tang, W. C., Tse, D. Y. Y., Tang, Y. Y., \& To, C. H. (2014). Defocus Incorporated Soft Contact (DISC) lens slows myopia progression in Hong Kong Chinese schoolchildren: A 2-year randomised clinical trial. British Journal of Ophthalmology, 98(1), 40-45. https://doi.org/10.1136/bjophthal mol-2013-303914

Morgan, I. G., French, A. N., Ashby, R. S., Guo, X., Ding, X., He, M., \& Rose, K. A. (2018). The epidemics of myopia: Aetiology and prevention. Progress in Retinal and Eye Research, 62, 134-149.

https://doi.org/10.1016/j.preteyere s.2017.09.004

Sankaridurg, P., Donovan, L., Varnas, S., Ho, A., Chen, X., Martinez, A., Fisher, S., Lin, Z., Smith, E. L., Ge, J., \& Holden, B. (2010). Spectacle lenses designed to reduce progression of myopia: $12-$ month results. Optometry and Vision Science, 87(9), 631-641. https://doi.org/10.1097/OPX.0b01 3e3181ea19c7

Shih, Y. F., Kate Hsiao, C., Chen, C. J., Chang, C. W., Hung, P. T., \& Lin, L. L. K. (2001). An intervention trial on efficacy of atropine and multi-focal glasses in controlling myopic progression. Acta Ophthalmologica Scandinavica, 79(3), 233-236. https://doi.org/10.1034/j.16000420.2001.790304.X

Smith, M. J., \& Walline, J. J. (2015). 
Controlling Myopia Progression in Children. Adolescent Health, Medicine and Therapeutics, 6, 133-140.

https://doi.org/10.32553/ijmbs.v4i 8.1332

Swarbrick, H. A., Alharbi, A., Watt, K., Lum, E., \& Kang, P. (2015). Myopia control during orthokeratology lens wear in children using a novel study design. Ophthalmology, 122(3), 620-630.

https://doi.org/10.1016/j.ophtha.2 014.09.028

Țone, S., Niagu, I. A., Bogdănici, Ștefan T., \& Bogdănici, C. M. (2020). Update in pediatric myopia treatment strategies. Romanian Journal of Ophthalmology, 64(3), 233-238. https://doi.org/10.22336/rjo.2020. 40

Walline, J. J. (2016). Myopia control: A review. Eye and Contact Lens, 42(1), 3-8. https://doi.org/10.1097/ICL.00000 00000000207

Wu, L. J., You, Q. S., Duan, J. L., Luo, Y. X., Liu, L. J., Li, X., Gao, Q., Zhu, H. P., He, Y., Xu, L., Jonas, J. B., Wang, W., \& Guo, X. H. (2015). Prevalence and associated factors of myopia in high-school students in Beijing. PLoS ONE, 10(3), 1-12. https://doi.org/10.1371/journal.po ne.0120764

Wu, P. C., Tsai, C. L., Wu, H. L., Yang, Y. H., \& Kuo, H. K. (2013). Outdoor activity during class recess reduces myopia onset and progression in school children. Ophthalmology, 120(5), 10801085. https://doi.org/10.1016/j.ophtha.2 012.11.009 
Jurnal Penelitian Perawat Profesional, Volume 3 No 3 Hal 445 - 452, Agustus 2021 Global Health Science Group 